\title{
Approaches to reduce noise from ships operating in important killer whale habitats
}

Authors:

Rob Williams, Pew Fellow in Marine Conservation, Oceans Initiative (USA) and Oceans Research and Conservation Association (Canada), rob@oceansinitiative.org

Scott Veirs, Beam Reach (USA), scott@beamreach.org

Val Veirs, Beam Reach (USA), val@beamreach.org

Erin Ashe, Oceans Initiative (USA) and Oceans Research and Conservation Association (Canada), erin@oceansinitiative.org

Natalie Mastick, Oceans Initiative, natalie@oceansinitiative.org

This is a pre-print version of a paper published in Marine Pollution Bulletin and should be cited as:

Williams, R., Veirs, S., Veirs, V., Ashe, E. and Mastick, N., 2018. Approaches to reduce noise from ships operating in important killer whale habitats. Marine Pollution Bulletin.

https://doi.org/10.1016/j.marpolbul.2018.05.015

Link to published version:

https://www.sciencedirect.com/science/article/pii/S0025326X18303229

\begin{abstract}
Shipping is key to global trade, but is also a dominant source of anthropogenic noise in the ocean. Chronic noise from ships can affect acoustic quality of important whale habitats. Noise from ships has been identified as one of three main stressors-in addition to contaminants, and lack of Chinook salmon prey-in the recovery of the endangered southern resident killer whale (SRKW) population. Managers recognize existing noise levels as a threat to the acoustical integrity of SRKW critical habitat. There is an urgent need to identify practical ways to reduce ocean noise given projected increases in shipping in the SRKW's summertime critical habitat in the Salish Sea. We reviewed the literature to provide a qualitative description of mitigation approaches. We use an existing ship source level dataset to quantify how some mitigation approaches could readily reduce noise levels by 3-10 dB
\end{abstract}

\section{Keywords:}

ship, noise, noise pollution, killer whale, endangered species

\section{Introduction}

Noise from global shipping traffic is now recognized as a chronic, habitat-level stressor (Jasny 2005, Weilgart 2007, Marine Mammal Commission 2007, Hildebrand et al., 2009, Simmonds et al. 2014, 
Dolman and Jasny 2015). Chronic ship noise can mask the range at which whales can communicate with conspecifics, and interfere with foraging activities (Clark et al. 2009). Over time, exposure to subinjurious levels of ship noise can cause physiological stress responses that may become apparent only when stress levels drop after noise sources are reduced (Rolland, 2012). Over the last decade, greater attention has been paid to the potential impacts of ship noise on the marine environment and the acoustic habitat upon which whale populations and other marine life depend (Marine Mammal Commission 2007, Clark et al. 2009, Weilgart 2007). Although knowledge gaps remain, the body of evidence now justifies responsible management to reduce ship noise levels (Radford et al. 2014).

Southern resident killer whales (SRKWs) are one of the most endangered marine mammal populations in the United States (Reynolds et al. 2011). Recovery of the this population hinges on the mitigation of three main factors: 1. limitation of their preferred prey (Chinook salmon, Oncorhynchus tshawytscha), 2. noise and disturbance that may disrupt foraging efficiency, and 3. contaminant levels (DFO Canada 2011). Periods of low Chinook abundance over the past several decades have been linked with reduced birth rates and lower survival of resident killer whales (Ward et al. 2009; Ford et al. 2010; Vélez-Espino et al. 2014). Both short term disturbance and chronic ocean noise from shipping and small boat traffic have been shown to disrupt foraging behaviour (Williams et al. 2006) and may mask both the social calls that killer whales use to coordinate group movements (Williams et al. 2013) and the echolocation clicks used to hunt salmon (Holt 2008). The effects of ocean noise may be amplifying the impact of prey limitation by interfering with killer whales' ability to locate and capture the limited salmon available.

The summertime core feeding habitat (Haro Strait, Washington State) for SRKWs (Hauser et al. 2007, Ashe et al. 2010) is among the loudest habitats measured along the Pacific Coast (Williams et al. 2013). A large and growing body of evidence suggests that the status quo (i.e., current levels of Chinook abundance and ocean noise) creates conditions that are untenable for SRKW recovery. However, it remains unclear how much noise levels would have to be reduced to promote SRKW recovery. Management targets for ocean noise (Williams et al. 2014b) and SRKW recovery (DFO Canada 2011) tend to be articulated in qualitative rather than quantitative terms. Quantitative management targets are rarely specified for cumulative impacts of multiple sublethal stressors, but they may be needed in the SRKW case where sublethal stressors are more important than lethal threats (e.g., fisheries bycatch, or ship strikes).

The exact mechanism by which SRKW foraging efficiency could be affected by current noise levels remains somewhat unclear, but one study found that SRKW spend $\sim 25 \%$ less time feeding in the presence 
of boats than in their absence (Lusseau et al. 2009). Another study found that SRKW were almost always accompanied by at least one vessel within $1000 \mathrm{~m}$ during daylight hours in summer months in Haro Strait (Williams et al. 2009). A study using Dtag technology found a significant relationship between vessel speed and noise levels received by killer whales (Houghton et al. 2015). A dose-response study showed that northern resident killer whales responded to received levels of ship noise $>120 \mathrm{~dB}$ (Williams et al. 2014a), which occurs commonly in Haro Strait (Veirs et al. 2016). This sensitivity to ship noise is problematic, because a number of large-scale industrial developments are pending that, if approved, would increase ship traffic in SRKW critical habitat (Gaydos et al. 2015). Some level of noise reduction will be needed to ensure that additional ship traffic does not cause a net increase in noise levels in SRKW critical habitat; in fact, some currently unspecified level of net reduction in noise will be needed to promote recovery given predictions of the SRKW trajectory under status quo conditions (Velez-Espino et al. 2014, Lacy et al. 2017).

This review outlines a suite of quantitative (i.e., analysis of existing data) and qualitative (i.e., based on a literature review) approaches through which managers could achieve reductions in ship noise. Where possible, we use existing ship source level data to illustrate how various mitigation scenarios could reduce broadband sound input levels in SRKW habitat. To gauge whether a noise mitigation measure is likely to cause a relatively large or small reduction in noise, we use a broadband $3 \mathrm{~dB}$ placeholder value to define a meaningful noise reduction underwater. This $3 \mathrm{~dB}$ value is notional until policy makers specify the level of risk they are willing to tolerate, but it happens to align closely with a pledge made originally by Okeanos and later endorsed by the Scientific Committee of International Whaling Commission (IWC Scientific Committee 2016). The "Okeanos pledge" calls for efforts to mitigate inputs from individual ships to "reduce the contributions of shipping to ambient noise energy in the 10-300 $\mathrm{Hz}$ band by $3 \mathrm{~dB}$ in 10 years and by $10 \mathrm{~dB}$ in 30 years relative to current levels" (Wright 2008).

We considered several scenarios to explore how a reduction of $3 \mathrm{~dB}$ in broadband levels of ship noise within SRKW habitat could be achieved. sThe scenarios were defined in response to science needs identified by Fisheries and Oceans Canada, but these scenarios do not reflect official policy of the Government of Canada. In most cases, this is equivalent to asking what is required to reduce the broadband source level of the ship by $3 \mathrm{~dB}$. In others, we quantify what measures could reduce broadband received levels by $3 \mathrm{~dB}$ (without alteration of the source level). In either case, a $3 \mathrm{~dB}$ reduction is equivalent to a halving of the total power radiated by the ship. This review focuses on noise inputs as broadband source levels (produced by the vessel), rather than received levels, time-area exposure, or impacts on individual killer whales or their population. In assessing some noise reduction options, we also 
considered temporal aspects of ship noise, like the timing of transits through Haro Strait and their speeddependent duration. However, we have not computed sound exposure levels (SEL), nor have we undertaken any spatio-temporal noise impact modelling specific to SRKWs.

1. Quantitative scenarios: Analysis of existing ship data

Shipping data collected within Haro Strait from 2011-2013 (Veirs et al., 2016) was analyzed to explore the potential acoustic consequences of a suite of noise mitigation measures described below (items 1a-1f). Our assessment of each mitigation measure is outlined in the conclusions and in many cases uses the methodology of Veirs et al. (2017). Veirs et al. (2017) identified that half of ship noise in Haro Strait comes from the noisiest $15 \%$ of the fleet. Here we explore how one could accomplish a $50 \%$ noise reduction through various mitigation scenarios, beyond simply removing the noisiest $15 \%$ of ships. We consider a range of practical ship noise mitigation measures, including speed limits, convoys, and rerouting.

Data set and methodology

The shipping data include estimated underwater source levels for 1,582 unique northbound ships that transited the core summertime habitat of SRKW during 28 months between March, 2011, and October, 2013. The ship source levels are based on calibrated measurement of received levels $(11.5-40,000 \mathrm{~Hz}, 2-$ second mean abeam, with background subtraction) near the shoreline of Lime Kiln State Park in Haro Strait (WA, USA) and a frequency-independent, near-spherical, spreading rate (transmission loss of -18.6 $\pm 0.4 \mathrm{~dB} /$ decade) based on a transmission loss experiment (Veirs et al. 2016).

To assess the relative noise contributions of different ships in the ship population, we integrated the source spectrum levels for each unique ship to estimate the total power radiated by each ship in a broad frequency band $(11.5-40,000 \mathrm{~Hz})$. After integration, we sorted the total radiated power levels, ranking them from lowest to highest. Then the power from each ship was summed (over all ships in the population) yielding the cumulative total radiated power - a distribution that we used to generate a quantitative assessment of a range of management options that would accomplish a $3 \mathrm{~dB}$ reduction in the total noise radiated by this population of ships (Veirs et al., 2017). Finally, individual ship source levels were converted from watts to $\mathrm{dB}$ re $1 \mu \mathrm{Pa} @ 1 \mathrm{~m}$. Note, however, that for brevity we abbreviate the units of all broadband levels (source and received) as " $\mathrm{dB}$ " in this report and use the terms "sound level" or "noise level" to refer to the broadband RMS intensity expressed in decibels. 
Convoy model methodology

While our existing data set cannot evaluate the spatio-temporal sound exposure levels for the moving ship sources and killer whale receivers, it can be used to investigate how modifying the speeds or temporal distribution of ships in Haro Strait would change the temporal (e.g., daily) distribution of received levels at a hydrophone location just offshore from Lime Kiln. To evaluate management options that alter the temporal distribution of ships, we built a "convoy model" (Veirs, 2017) that uses the source levels from the ship population to compare a noise scenario representing current conditions with select noise management options (specifically items 1a, reducing the speed of vessels, and 1f, the convoy approach). This model allows us to explore a variety of distributional and temporal transit scenarios (i.e., changes in speed and convoy composition) and evaluate how much each scenario changes noise levels (Figure 1).

The convoy model uses a probability function to determine when a new vessel should appear at each minute throughout a model year. This probability was chosen to achieve the desired number of ship transits (7,500/year under current conditions). For each ship that appears, it is randomly assigned the identity and associated attributes of one of the 2,809 isolated transits in the population of Veirs et al. (2016). Using the assigned speed over ground and source level, the ship is launched randomly, either northbound or southbound, from a distance of $10 \mathrm{~nm}$ north or south of the study site (the nearshore hydrophone at Lime Kiln). While each ship moves at a specified speed in its specified lane, the received level at Lime Kiln is calculated for each minute of the transit. 


\section{Veirs' Convoy Model}

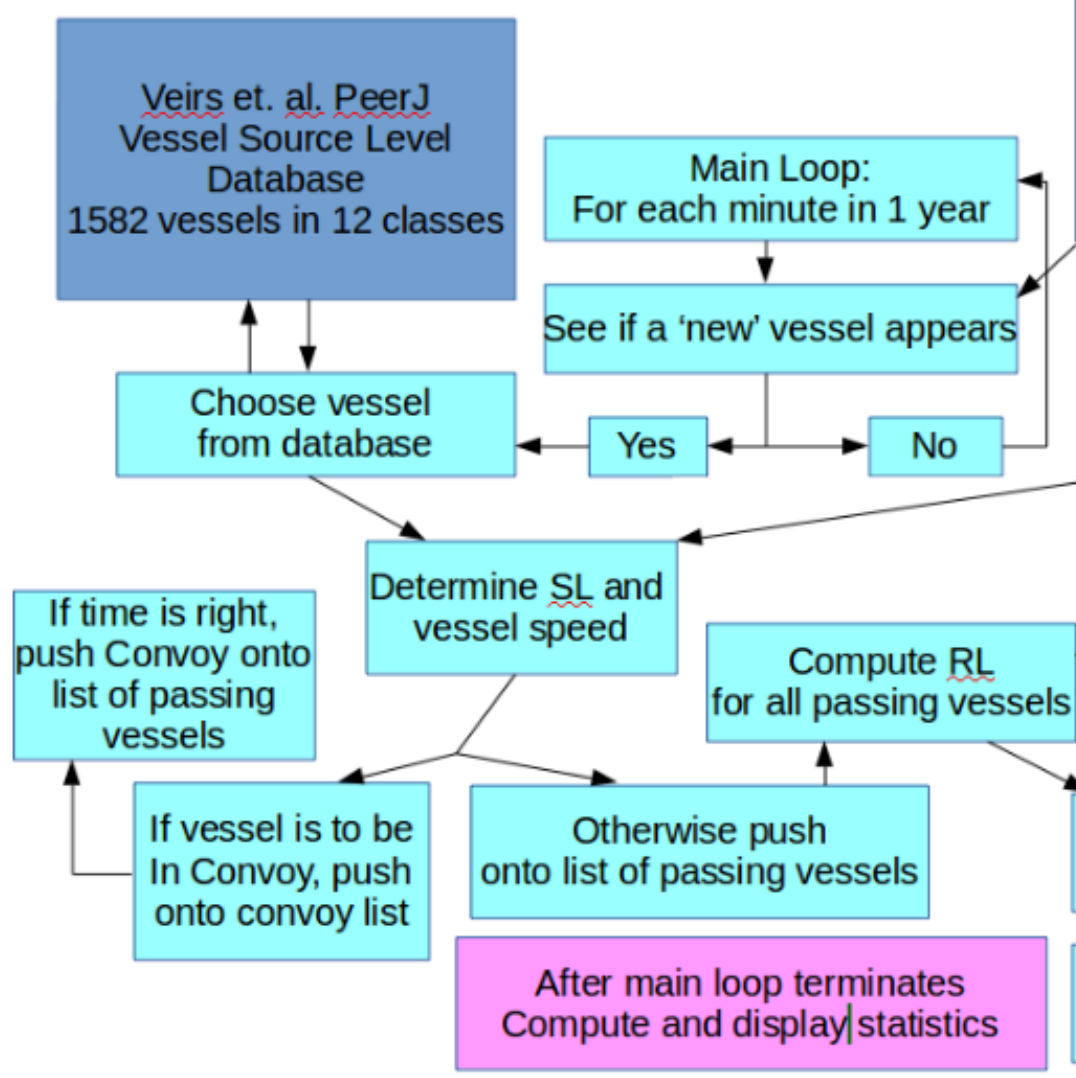

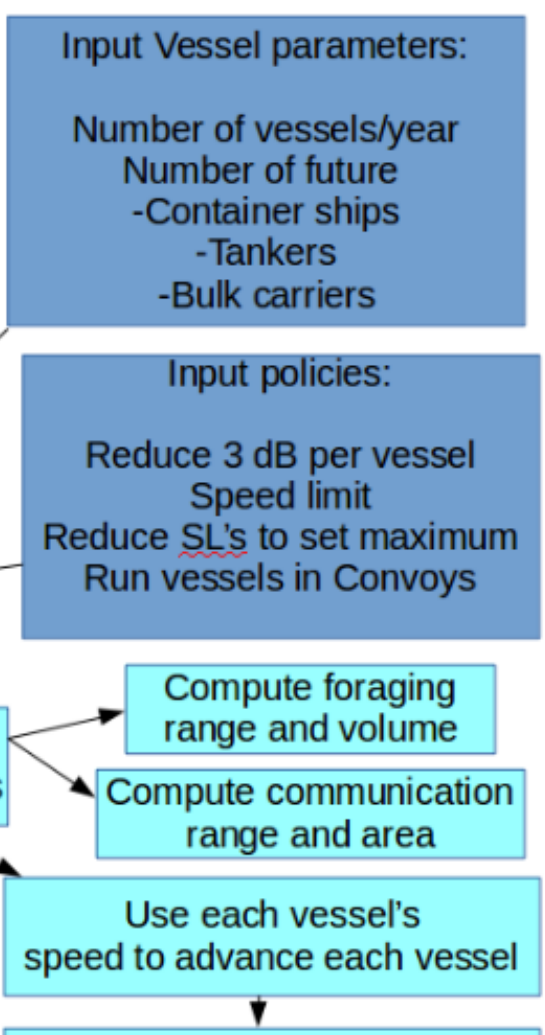

Delete from passing vessel list any vessels that go out of range

Figure 1: Schematic of the convoy model (Veirs, 2017). The Main Loop runs minute-by-minute through the ship population (e.g. current amount of traffic [ships/year for each class] arriving randomly on any given day, or some future scenario with altered traffic rate) checking if a new ship appears. When one does, a representative ship is retrieved from the database of Veirs et al., 2016, thereby obtaining an initial speed and SL to combine with the time of day (from the main loop). If the ship speed is not above a specified speed limit, the ship proceeds through model space (e.g. Haro Strait, or other space where a key parameter is the acoustic range within which the acoustic impact of a ship or multiple ships is assessed) generating a distribution of $R L$ vs time at Lime Kiln based on assumed spreading rate. If the ship speed is above the specified speed limit, the initial speed is reduced along with a proportional reduction in $S L$ (based on observed general $1 \mathrm{~dB} / \mathrm{kt}$ relationship). These slowed ships either proceed through the model space, or are added to a convoy list and do not proceed through the model space until the next specified convoy time. After the main loop terminates (e.g. finishes a 1-year simulation), a suite of metrics is computed and displayed, including the cumulative distribution of received levels (e.g. Figure 4), or SRKW-specific foraging vocalization metrics like foraging range and volume, or communication range and volume.

The results of the modelling scenario representing current conditions are presented in Figure 2. The primary output of the convoy model is the cumulative percentage of time that the received level (RL) is less than any specified decibel level $(\mathrm{dB})$. For example, the black curve in Figure 2 indicates that under 
"current conditions" (2012 dataset), $50 \%$ of the time RL is below $104 \mathrm{~dB}$, and $75 \%$ of the time RL is below $\sim 109 \mathrm{~dB}$.

The effect of convoys and speed changes were explored by implementing a range of scenarios in which the following parameters were altered: speed limit; number of ships per convoy; timing of convoys (number per day, duration, times of day); and distribution of ships in a convoy (e.g., single-file or in parallel "lines").

\section{1a. Reducing the speed of vessels}

In many ships, a $1 \mathrm{kt}$ reduction in speed leads to a $1 \mathrm{~dB}$ reduction in broadband source level (Veirs et al. 2016). We used this general relationship to assess the mitigation option of reducing the speed of all ships in areas of likely noise-whale interactions (i.e., Haro Strait). Management actions targeting only specific vessel classes would require additional analyses, and some classes (e.g., fishing boats) are too rare to offer the potential to reach a $3 \mathrm{~dB}$ reduction. We assume that the relationship described above should apply to the fleet as a whole.

Following the methodology of Veirs et al. 2017, the fleet-wide speed limit needed to achieve a $3 \mathrm{~dB}$ reduction was derived through an iterative process by: 1) reducing the speed of each of the loudest ships to the selected speed limit; 2) imposing a proportional reduction in the source levels; 3) integrating the new source level distribution; and 4) assessing whether the reduced total power (i.e., watts) equaled half of the initial total power.

In the study area, a $3 \mathrm{~dB}$ noise reduction target could be met by enforcing a speed limit of $11.8 \mathrm{kt}(6.1$ $\mathrm{m} / \mathrm{s}$ ), which would impact $83 \%$ of the ship population. For comparison, the mean and standard deviation of the speed distribution is $14.1 \pm 3.9 \mathrm{kt}$ for the ship population and $19 \pm 2 \mathrm{kt}$ for the fastest class (i.e., container ships).

Under this management option, faster-moving ships would be required to make a larger absolute speed reduction than slower ships. Ship classes with mean speeds above the $11.8 \mathrm{kt}$ limit include not only container ships, but also vehicle carriers (mean speed of $16.9 \mathrm{kt}$ ), passenger (cruise) and cargo ships (both $14.4 \mathrm{kt})$, tankers $(13.8 \mathrm{kt})$, bulk carriers $(13.7 \mathrm{kt})$, and pleasure craft $(12.4 \mathrm{kt})$. In contrast, slower vessels such as tugs $(8.2 \pm 2.3 \mathrm{kt})$, fishing vessels $(9.1 \pm 2.2 \mathrm{kt})$, research ships $(11.1 \pm 1.8 \mathrm{kt})$, and military ships $(11.1 \pm 3.1 \mathrm{kt})$ would be largely unaffected by this management option due to mean speeds that fall well below the proposed speed limit. 
The convoy model can be used to obtain a different, but essential, perspective on the effect of limiting the speed of vessels to $11.8 \mathrm{kt}$. First, we define the current temporal distribution of ships as random passages of $\sim 7500$ ships/year, based on the long-term average of 20 ships/day transiting Haro Strait (Veirs et al., 2016; Veirs \& Veirs, 2006). We then institute a speed limit of $11.8 \mathrm{kt}$ which reduces the source levels of many ships, but also increases the duration of the reduced received levels (because many ships are slowed). The overall effect of these two changes on the temporal distribution of received levels is indicated by the red dotted curve in Figure 2 .

Note that imposing a speed limit mitigation option raises the curve relative to current conditions in the $\mathrm{dB}$ range 105-120 dB (Figure 2), constituting an acoustic improvement. In the current situation (black dotted curve), SRKWs would receive noise levels of $110 \mathrm{~dB}$ or less for $80 \%$ of any day(s) they spend near the Lime Kiln shoreline, whereas if the 11.8-kt speed limit were implemented the whales would experience levels $\leq 110 \mathrm{~dB}$ for $85 \%$ of the time. Thus, the speed limit reduces the time SRKWs receive peak levels $(>110 \mathrm{~dB})$ by $\sim 5 \%$, or about 1.2 hours per day.

At received levels below $\sim 105 \mathrm{~dB}$ there is a subtle effect in the opposite direction. For example, the daily duration of received levels less than $\sim 103 \mathrm{~dB}$ would increase by $\sim 1-2 \%$ for SRKWs at Lime Kiln if a speed limit were implemented, because the slowed ships ensonify Haro Strait for a longer period. Thus, under a 11.8-kt speed limit, the "quiet time" experienced by SRKWs could decrease by $\sim 15-30$ minutes/day.

\section{1b. Removing the noisiest ships}

An iterative method (Veirs et al., 2017) was used to assess the impacts of removing the noisiest ships ("gross polluters"). After calculating the total radiated power from the initial ship population, the noisiest ship was removed from the population and the total radiated power was re-calculated. If the initial total power was not halved following this removal, the process was repeated.

The results (Veirs et al., 2017) indicate that the total power radiated by this ship population could be reduced by half by removing the noisiest $15 \%$ of the shipping fleet $(\mathrm{n} \approx 240$ ships $)$. This management option would mostly affect the bulk carrier, container, tanker, and cargo ship classes. A total of 232 ships would be affected across these classes, including $43 \%$ of all container ships, $17 \%$ of cargo ships, $13 \%$ of bulk carriers, and $12 \%$ of tankers (Figure 3 ). 


\section{1c. Retrofitting vessels}

Ship source levels can be reduced through retrofitting vessels with noise reduction technologies. The reduction threshold was calculated using an iterative approach, by which the source level of the loudest ship was reduced to the level of the next-loudest ship in each iteration until the total power radiated by the population was halved.

The number of ships affected by this approach are shown in Figure 3. The number of affected ships as a percentage of both our population and, where applicable, the total number of ships in each class are also tabulated to allow easy extrapolation to the global fleet or other regional subpopulations.

The total power radiated by this ship population could be cut in half by reducing the source levels of the loudest $42.8 \%$ of the fleet ( $\approx \approx 677$ ships). In our population of container ships, almost $90 \%$ would be affected by the noise reduction option.

The maximum reduction required to halve the fleet's total power is about $10 \mathrm{~dB}$ for the loudest ships. Such a noise reduction should be attainable with currently available ship-quieting technologies (Southall \& Scholik-Schlomer 2008) and techniques (Baudin \& Mumm 2015).

\section{1d. Changing ship design (replacing noisy ships with quieter new ships)}

When selecting management options to assess in Veirs et al. (2017), we considered modelling a scenario in which ships with the highest source levels were replaced with quieter ships. It is unclear which value to use for new, quieter ships. Removal and replacement could involve replacing noisy ships with new ships that are assumed to have broadband source levels equivalent to the mean, median, or minimum levels of ships in the current fleet.

For many types of new ships, a $10 \mathrm{~dB}$ reduction in source level can be achieved with only a $1 \%$ increase in design/construction costs (Spence \& Fischer 2016). Barring a more realistic scenario, we could model replacement of the noisiest $15 \%$ of ships (using the cutoff identified by Veirs et al. (2017)) with quieter ships having $10 \mathrm{~dB}$ lower source level.

\section{1e. Relocating shipping traffic lanes}

Shifting a shipping lane laterally away from SRKW habitat would increase the range to the source of ship noise. We imagine such fine-scale shifts being in the range of a few hundred meters to a few kilometers, 
and that in many parts of the Salish Sea, navigational hazards or the adjacent coastlines will constrain the feasibility of this approach. Rerouting shipping (e.g., from Haro Strait to Rosario Strait) is equivalent to the removal option (1b) from the perspective of the local SRKW habitat (e.g., near Lime Kiln). We note that any relocation of a ship without reduction of its source level may reduce received levels in an area of interest, but it will also increase received levels in the area(s) towards or into which the ship is moved, possibly in proportion to the reduction (if other variables like spreading environment are equivalent).

To estimate the acoustic effect of moving traffic lanes, we searched the database of Veirs et al. (2016) for ships with at least 10 repeat transits of Haro Strait in both the northbound and southbound lanes. We analyzed only the container ship class for this report because: container ships are on average the class with the highest source levels; the sample size is large (compared to other classes there are more repeat transits by any single ship); and we assume that the loading of container ships may not change much because containers are not very dense compared to bulk goods. The latter is important because variable loading could cause large fluctuations in source level by altering propeller depth which is a strong control on the inception of cavitation — the primary source of ship noise (Ross, 1976).

Southbound transits at ranges of $\sim 2.75 \mathrm{~nm}$ had lower received levels than the northbound transits, which are $\sim 1.5 \mathrm{~nm}$ closer to shore (range $\sim 1.25 \mathrm{~nm}$ ). The median of these slopes is $-1 \mathrm{~dB}$ per nm-negative as expected-despite some individual ships having positive slopes. Note this slope cannot be applied over other distances in this area, nor in other areas where the spreading environment could differ.

Importantly, we found many cases in which the more distant southbound transits had equivalent or even higher average received level than closer, northbound transits of the same ship. We believe that because of reverberation in Haro Strait, a steep-sided, relatively unsedimented channel, there is often little systematic difference between the received levels from northbound versus southbound ships. It is also possible that the lack of a systematic difference could be due to variations in the source levels in northbound versus southbound lanes (e.g., as a consequence of loading differences or athwartship [starboard-port] asymmetry in the radiated noise). Hence, we conclude that moving the shipping lanes farther from Lime Kiln Point is unlikely to be an effective way to reduce noise for killer whales foraging along the shoreline.

Additionally, within much of the Salish Sea, moving a lane is limited by coastlines and bathymetry. Thus, we believe that a reduction of more than $1-2 \mathrm{~dB}$ is unlikely for this management option, no matter where it is applied. 


\section{1f. The convoy approach}

A speed limit on ships could simplify the logistics of the moving ships into and out of ports in convoys, because most large ships would be traveling at the same speed. Alternatively, convoys could form by having ships stage at a low-risk location (e.g., Port Angeles harbor for inbound ships and near Vancouver for outbound ships) and then proceed together at some fixed speed (not necessarily a speed limit).

Grouping the ships into convoys dramatically changes the temporal distribution of ship noise over the day and night. In general, a single group of inbound ships could transit Haro Strait (the $40 \mathrm{~nm}$ from Constance Bank to East Point) in a limited part of each day (i.e., in one 4-hour interval for the inbound ships and a second 4-hour period later in the day for outbound ships). Separated by several boat-lengths, a convoy would pass a point such as Lime Kiln in about an hour. If the convoy were organized in two parallel groups that still fit safely within the lane, the transit time would be halved. For comparison, the duration of ship noise in Haro Strait under typical conditions is $\sim 10-15$ hours per day (roughly 20 ships/day, each raising background noise levels at Lime Kiln for 30-45 minutes).

On the other hand, transiting in convoys would increase the received level above current typical maxima at any particular point of closest approach. Outside of the hour in which the convoy passes, though, there might be long periods in which no ship would elevate ambient noise levels. This would increase maxima occasionally, but would also increase periods of quiescence.

To assess the convoy approach more quantitatively, we group a day's worth of inbound ships by randomly selecting them from our population of ships that have speeds exceeding the $11.8 \mathrm{kt}$ limit. The group is released at 6 a.m. with $\sim 7$ ships/convoy organized single-file, separated by a ship-length (a spacing recommended to us via personal communication with an experienced ship captain). A second group of outbound ships is run 10 hours later (at 4 p.m.) in the opposite direction. The result is depicted in Figure 2 along with the current traffic and speed-limited cases for comparison. We created a user-friendly graphical interface to allow easy modifications to the inputs used in these scenarios (available via QT code of Veirs, 2017). 


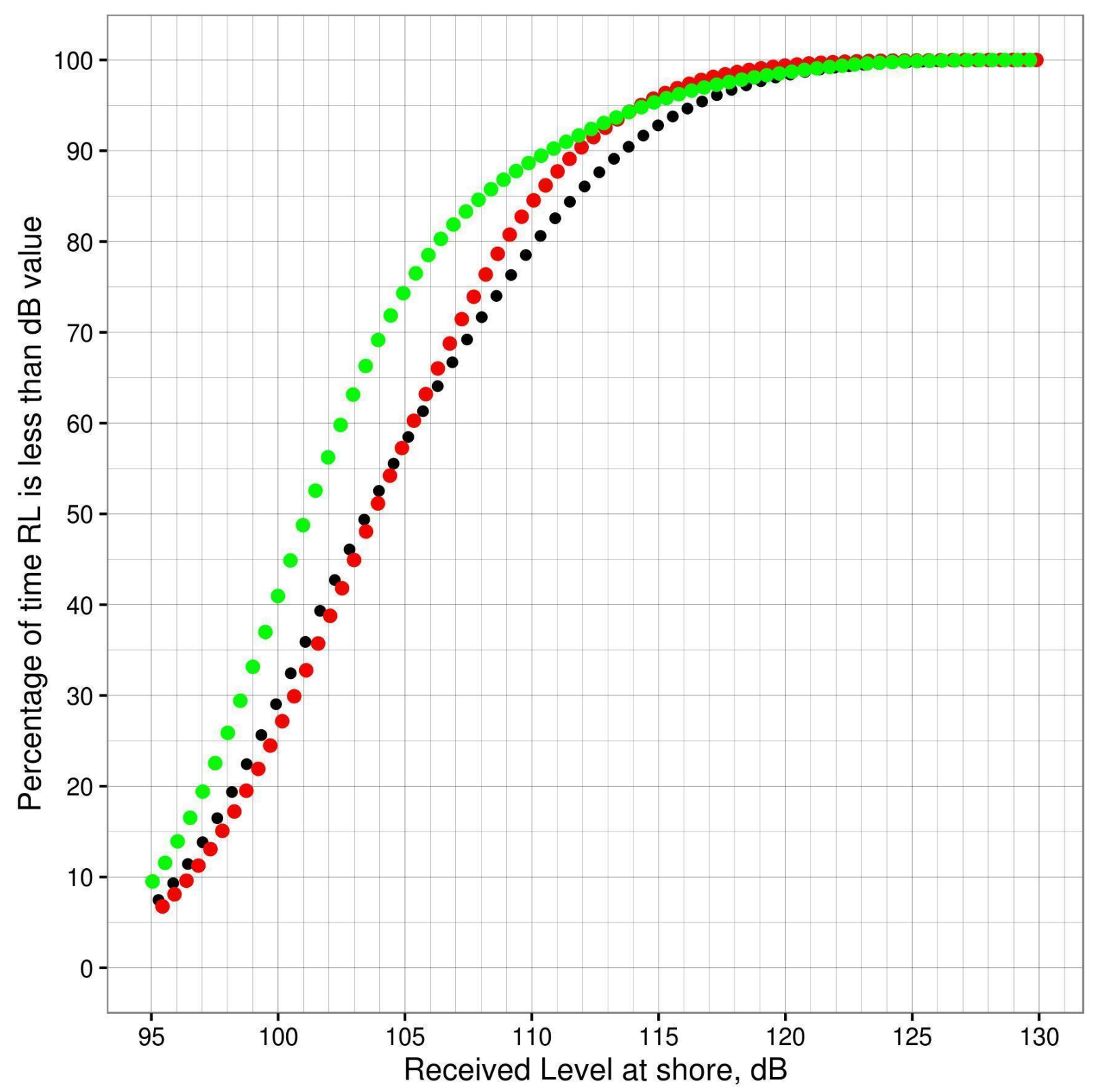

Figure 2: Cumulative distribution of received level (RL) at Lime Kiln. Each curve represents the percent of time (e.g. hours of a day) that the received level at Lime Kiln is below a given level. Black depicts modeled distribution for current conditions (parameterized with observed ship source levels and temporal distribution), e.g. 50\% of the time RL is less than $104 \mathrm{~dB}$. Red shows the modeled distribution for a $11.8 \mathrm{kt}$ speed limit. Green represents a management option involving both an $11.8 \mathrm{kt}$ speed limit and a convoy approach (1 northbound and 1 southbound convoy per day, each averaging 7 ships), e.g. RL is less than $101 \mathrm{~dB}$ for half the day (a $3 \mathrm{~dB}$ reduction in median received level).

The change from current traffic conditions (black) to the convoy-plus-speed-limit mitigation option 
(green) is much larger than the change from the current situation to the speed limited strategy (red). Also, at the lowest received levels, the convoy-plus-speed-limit option causes an increase in the percent of time $\mathrm{RL}$ are below these low values, an acoustic improvement which did not occur with the speed limit alone. For initial received levels of 104-112 dB (corresponding to $50-80 \%$ of the day, or any other continuous time period spent near Lime Kiln) the convoy-plus-speed-limit option lowers received levels by $\sim 3 \mathrm{~dB}$.

Summary: quantitative comparison of noise mitigation scenarios

For the six noise mitigation scenarios (a-f) that we could explore quantitatively, we summarize the findings in Figure 3. Figure 3 provides an overview of the number and class of ships that would be affected by each mitigation strategy to accomplish the same noise reduction target.

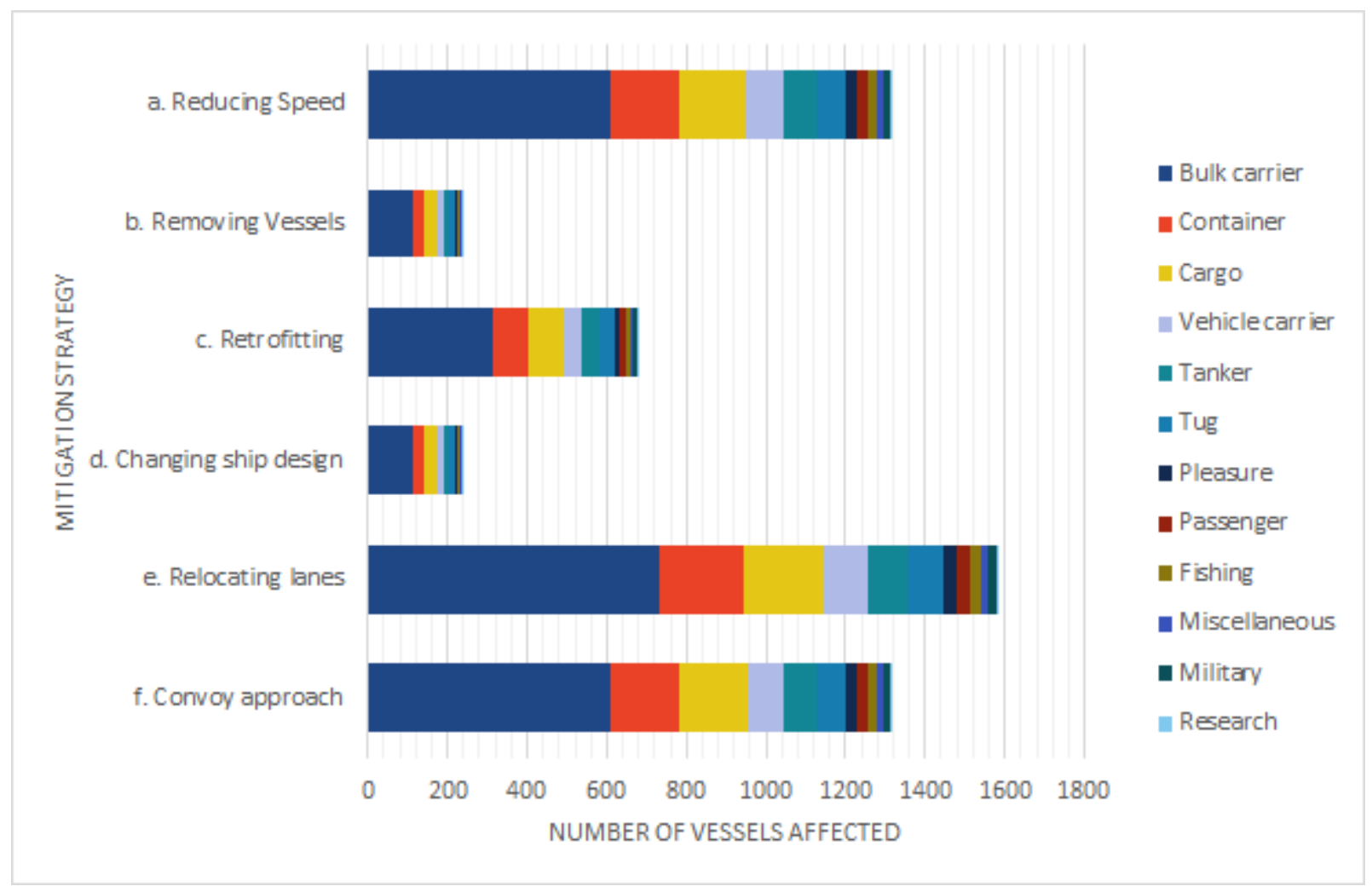

Figure 3: Noise mitigation strategies and number of vessels affected, as predicted by each model. Note that two pairs of scenarios (i.e., $A$ and $F$, and $B$ and $D$ ) are equivalent mathematically but distinct logistically. The scenarios are treated separately, because they would involve quite different real-world management implications and economic costs. 


\section{Qualitative scenarios:}

This section provides an executive summary of our literature review for several noise reduction and mitigation strategies, including short term, seasonal, and long-term management strategies, as well as ship-based management. Although each scenario is described in greater detail in an annotated bibliography (Appendix 1), we provide a brief summary below of our professional opinion of the potential scope of mitigation offered by each scenario. Each scenario involves additional input from a policy perspective on quantitative conservation targets and from an industry perspective on costs and practicalities of implementation.

\section{2a. Area-Based tools}

\section{i. Short-term management}

Real-time notification and avoidance: technologies exist to couple real-time SRKW detection and ship notification systems to trigger short-term mitigation measures. Real-time monitoring for cetaceans has been considered for pile-driving during wind-farm construction (Berkowitz \& Dumez 2017). A real-time listening buoy alerts mariners to presence of North Atlantic right whales to reduce the probability of ship strikes ${ }^{1}$. A cabled system (like the Orcasound project $^{2}$ ) could monitor for SRKW signals in real time. The outstanding issue is how to convey that information to mariners, and what to ask them to do with the information. NOAA uses Cornell's real-time detections of right whale calls to alert mariners via AIS through their WhaleAlert app ${ }^{3}$. However, ships are unlikely to be able to make rapid adjustments to course and speed in response to real-time whale detections. Therefore, the notion of a rapid response strikes us as impractical in the confined waters of the Salish Sea, given navigational safety concerns. One study on the efficacy of real-time detections of cetaceans by marine mammal observers on seismic survey vessels found that ships were simply unable to respond quickly enough to a whale detection to mitigate accordingly (Leaper et al. 2015). Leaper et al. (2015) showed that conducting real-time observations to trigger seismic survey shutdowns was less effective than simply reducing source levels of airguns, given imperfect detectability of cetaceans at sea and the navigational constraints governing response time. We suspect that mariners trying to avoid killer whales will experience similar issues when incorporating realtime detections into their travel routes in a busy shipping lane in a narrow strait. That said, practical issues of maritime safety are outside the remit of this current study, and we therefore encourage discussions with

1 http://www.listenforwhales.org/Page.aspx?pid=430

2 http://www.orcasound.net/

3 https://www.nefsc.noaa.gov/press_release/pr2014/scispot/ss1411/ 
a wider group of stakeholders and experts on this issue.

\section{ii. Seasonal management}

Changes in timing of ship traffic: this scenario refers to medium-term, dynamic marine management, including Marine Protected Areas, over seasonal scales. We see two main arguments for the use of dynamic area management approaches on a seasonal temporal scale. On the acoustic side, seasonal oceanographic processes may hinder or facilitate long-range sound propagation of ship noise (McKenna et al. 2013). On the biological side, highly migratory species (e.g., baleen whales) may be absent in some seasons, in which case restrictive measures may only be required in high-use periods (Vanderlaan et al. 2008). The SRKW population is seen in all months of the year in Haro Strait, but is seen more commonly in summer months than in winter (DFO Canada 2011).

One limitation to seasonal management is the lack of unbiased estimates of SRKW density and distribution on a monthly or seasonal scale. Most analyses of SRKW distribution do not take search effort into account, which risks underestimating the importance of areas on the periphery of the SRKW range (Miller et al. 2013). A spatially explicit analysis is needed to quantify the proportion of the SRKW population that would benefit from static (year-round) versus dynamic mitigation measures, including time-area closures. It may be that the whales spend little time in their core area outside the summer months, but that they visit the area in the winter months primarily for feeding. If so, mitigation focused solely on summer months may be inadequate to promote SRKW recovery.

\section{iii. Long-term management}

Speed limits: there are many case studies around the world to draw from when considering a mitigation scenario that reduces speed (of all vessels or a specific vessel class) in areas of likely noise-whale interactions, such as SRKW critical habitat (e.g., Haro Strait, Swiftsure Bank, etc.). Most of the case studies we found are academic exercises quantifying how much noise levels could be reduced by reducing speed. These can also be modelled using data from other studies designed to model reduction in ship strike risk or fuel efficiency as a consequence of speed restrictions. A study on soundscapes in the Saguenay-St. Lawrence Marine Park found that speed limits could reduce the average noise level produced by the fleet by $4.6 \mathrm{~dB}$, but that the strong variability in source level among vessel classes could result in unintended consequences for St. Lawrence Estuary beluga (Gervaise et al. 2012). One study on cruise ships found a $5 \mathrm{~dB}$ reduction in source level with a $3.3 \mathrm{kt}$ reduction in speed (Spence \& Fischer 
2016). A further study in Haro Strait found a reduction of $1.8 \mathrm{~dB}$ for every $1 \mathrm{~m} / \mathrm{s}$ reduction in speed (0.93 $\mathrm{dB} / \mathrm{kt}$ ), with considerable variability among vessel classes (Veirs et al. 2016). A temporary speed restriction was used in Glacier Bay, AK to reduce effects of ship noise on humpback whales ${ }^{4}$. One industry-led effort - "slow steaming" - reduced ship speed to improve fuel efficiency, but may have also had unintended side benefits, e.g. reducing probability of lethal ship strikes as well as underwater noise levels. Safe navigation requires some minimum speed for particular vessels and ocean conditions, but determining such minima is beyond the scope of this review. For many ship classes one method of attaining a $3 \mathrm{~dB}$ reduction - proposed in Veirs et al. (2017), i.e., slowing to at least 11.8 knots (over the ground) -- has been judged by local pilots to be logistically feasible and safe.

Relocation of shipping traffic lanes: in this study, we report a linear relationship between range and distance - specific only to Haro Strait — in which a $1 \mathrm{~dB}$ reduction in source level is observed when the range to the source is increased $\sim 1 \mathrm{~nm}$ (section 1e). There is considerable variation around that observed relationship and with a simple spreading model, we show that a theoretical, typical logarithmic relationship can lead to a wide range of noise reductions, many of which are $<3 \mathrm{~dB}$. As a first-order approximation, we estimate that in typical spreading environments, it would take a $1-4 \mathrm{~km}$ shift in the shipping lanes away from a nearby SRKW high-use area to reduce noise levels by more than $3 \mathrm{~dB}$.

Larger-scale shifts in shipping lanes (e.g. moving ships from Haro to Rosario Strait, a nearby shipping lane that stretches between mainland Washington and the San Juan Islands) may have the added benefit of reducing the probability of lethal ship strikes. Changes in shipping lanes have been implemented to reduce ship strike risk to baleen whales off southern California (Redfern et al. 2013) and right whales off eastern Canada and the US (Silber et al. 2012). In a framework aimed at reducing habitat-level ship noise inputs or impacts to multiple species, one may adopt a traffic dilution scheme (e.g., (Baudin \& Mumm 2015)). This creates lower levels of noise throughout the habitat, rather than having quiet and noisy areas (Williams et al. 2015a; Erbe et al. 2014). SRKW have extreme site fidelity to the west side of San Juan Island in summer months, so it should be feasible to use "least-cost routing" methods (Best 2016) to quantify the benefit to whales by redirecting a portion of ship traffic. This would require unbiased information on SRKW distribution and abundance. Mathematically, the scope of rerouting ships is equivalent to simply removing that same proportion of ships from the fleet using Haro Strait (i.e., the scenario modelled and described in 1B). From a biological perspective, removing and rerouting ships may have dramatically different consequences. Choosing between these two mitigation measures would

$4 \quad$ https://www.nps.gov/glba/learn/news/2009722.htm 
require spatially explicit analyses of ship traffic, SRKW distribution, and SRKW habitat use.

Feedback is needed on the amount of noise reduction desired, and in what currency (e.g., broadband or audiogram-weighted levels; tradeoffs between amplitude and duration). Additionally, there are navigational constraints to the relocation of shipping lanes, especially in confined waters such as Haro and Rosario Straits. The more concentrated the whales are in a discrete area, the easier it is for ships to reduce received levels in that area by staying farther away. Additional research is needed to integrate information on the distribution of ships and the distribution of whales.

Creation of 'quiet'/'no-go' areas, or periods of quiescence: Marine Protected Areas (MPAs) remain one of the most powerful tools available for separating marine wildlife from harmful human activities (Agardy et al. 2003). We see value in articulating, explicitly, a management objective to reduce noise levels along parts of the shipping route. Previous work has proposed statistical methods to identify areas that SRKW use preferentially for feeding (Ashe et al. 2010), which is the activity state in which SRKW are most vulnerable to disturbance (Lusseau et al. 2009). This approach would fit nicely in a systematic conservation planning framework (Margules \& Pressey 2000). Conceptually, the novel part of this scenario is simply articulating a management objective in spatial terms: e.g., protecting $50 \%$ of SRKW critical habitat, with an emphasis on areas used preferentially for feeding. These quantitative management objectives are called conservation targets in a systematic conservation planning process, and the targets could involve seasonal or year-round protection. There is growing interest in developing quiet (or quieter) MPAs (Williams et al. 2015a), but to the best of our knowledge, no agency has explicitly integrated ocean noise into an MPA management plan. That being said, the high traffic levels and ability of ship noise to propagate long distances make it unlikely that any part of SRKW habitat will become truly quiet; it is too urbanized to become acoustically pristine. The biggest barrier to creating quieter MPAs, in our opinion, is the issue of jurisdiction. The MPA management plan must take into account noise-generating activities both inside and outside the boundaries, which would require multi-stakeholder and agency collaboration and international cooperation.

Convoy approach (staged vessel movements): our analysis of a previously published database of ship source levels (Veirs et al. 2017) revealed that a convoy approach would increase quiet periods dramatically. The convoy scenario we modelled would reduce the 50th percentile of the noise distribution from $\sim 104$ to $\sim 101 \mathrm{~dB}$ (Figure 6). As part of this exercise, one of us (V. Veirs) developed a graphical user interface to rerun convoy scenarios exploring mitigation measures with different vessels or vessel classes, or alternative timing windows. For safety reasons, a convoy would also include management of speeds. 
This offers the potential to combine modeled mitigation scenarios. Convoys involve fine-scale management of ship movements, which raise questions of navigational efficiency, safety, and port operations. While exploring the feasibility of any particular convoy scenario was beyond the scope of this review, it would be possible to rerun the convoy scenario using our model to estimate plausible noise reduction levels after stakeholder review.

\section{2b. Ship-based management}

\section{i. Changes in shipping practices}

There are few empirical studies to explore how changes in shipping practices may translate to reduced underwater noise. The most comprehensive study we are aware of is the AQUO study (synthesized in Audoly et al. (2016)). In a series of linked papers, Audoly and colleagues found modest $(<3 \mathrm{~dB})$ reductions in noise from all changes in shipping practices considered, including: optimized ship handling, hull and propeller cleaning, propeller plant configuration, and appropriate management of the dynamic positioning system. One minor point to explore on shipping practices in Haro Strait stems from a study showing that cargo ships tend to be quieter when fully loaded than when they are running half empty, because the propeller is designed to work with a fully loaded vessel (Andre et al. 2011). Regrettably, we were unable to determine how much this issue affects source level, which makes it difficult to quantify how effective this would be as a mitigation measure. If it were possible to obtain loading information from AIS or the Coast Guard, it would be possible to incorporate this into studies in the Strait of Georgia or Lime Kiln to estimate within-ship variability in source level as a function of operational factors like maintenance or loading.

\section{ii. Changes in ship design and modifications/retrofits}

There is considerable scope to make new ships quieter than existing ships in the fleet. One study estimated that a reduction of up to $10 \mathrm{~dB}$ in source level is achievable for a $1 \%$ increase in build costs over conventional designs (Spence \& Fischer 2016). Even more dramatic noise reduction (20-40 dB) on new ships may be possible with $\sim 10-15 \%$ in additional building costs (Southall 2005). To reach the upper range of the expected benefits from a new build, shipbuilders must consider all of the main recommendations listed in this section and elsewhere (e.g., Sections 2D and 2F). The contribution of any one mitigation measure alone will be modest. Audoly et al. (2016) note that there is a complex interplay between ship design and operation. Importantly, the benefits of speed reduction may not apply equally between ships with conventional and controllable pitch propellers. Some AQUO studies showed that 
varying blade pitch settings can significantly reduce and even suppress propeller cavitation (Audoly et al. 2016).

The biggest scope for noise reduction via retrofit is through replacing conventional propellers with ones that are optimally designed for quiet operation of that ship (Spence \& Fischer 2016). Improved propellers (e.g., Contracted Loaded Tip or CLT propellers) can be incorporated to the design or added to a retrofit without requiring modifications to the hull. Some propeller designs (e.g., forward-skewed nozzlepropeller blades) increase cavitation inception speed and reduce cavitation, and therefore noise produced (Southall \& Scholik-Schlomer 2008). Variable pitch propellers can reduce noise, but the reduced efficiency and high cost may be barriers to commercial uptake (Southall \& Scholik-Schlomer 2008). That said, these design modifications may be less costly to industry than speed restrictions or route modifications. Reducing noise through propeller design seems most promising when coupled with other design considerations (e.g., improving wake flow upstream of the propeller). Air injection systems may allow ship noise to be effectively masked, thereby reducing noise levels by $10 \mathrm{~dB}$ or so (Spence et al. 2007). There is some concern that air injection systems can reduce noise levels above $500 \mathrm{~Hz}$, but actually increase levels of low-frequency noise (Spence et al. 2007). Together, propeller modifications and air injection systems may be appropriate ways to mitigate noise inputs in SRKW critical habitat, given the poor hearing ability of killer whales at frequencies below $500 \mathrm{~Hz}$ (Hall \& Johnson 1972; Szymanski et al. 1999). Within the ship, modifications to the way that machinery (e.g., medium speed diesel engines and diesel generators) is mounted to the hull can also reduce radiated underwater noise levels. Ships that do not already employ such "foundations" could retrofit them to achieve reductions in radiated noise of 15-20 dB (Wright 2008).

Much of the research on quieter ships addresses ways to reduce noise at speeds below cavitation inception speed or raising the cavitation inception speed as high as possible. While this may be attractive for military or research vessels, owners and operators of large merchant ships may not be willing to accept the associated loss in efficiency (IMO-MEPC 2009). There may be a specific scenario (e.g., an extremely noisy ferry transiting an important killer whale feeding area daily) that may warrant prioritizing the design and construction of a quieter ship immediately. Retrofitting old vessels, generally speaking, carries greater technological and financial costs to reduce underwater noise than new builds. At the level of the commercial shipping fleet we consider new builds and retrofits to be part of a broader discussion of scenarios involving removal or removal and replacement of the noisiest ships. Adding relatively quiet ships to a noisy fleet, without removing or replacing noisy ships, will not reduce noise input overall. We suggest having discussions with naval architects and mariners, who will have complementary expertise 
that may cause us to revisit these conclusions and recommendations.

\section{iii. Changes in maintenance of ships}

A number of studies have suggested that regular hull and propeller maintenance should increase fuel efficiency and reduce underwater radiated noise (Southall 2005; Baudin \& Mumm 2015). There seem to be outliers in which individual ships have higher than expected noise levels for a given size, class, and speed (McKenna et al. 2013; Veirs et al. 2016). The cause of these outliers is unknown, but may relate to propeller damage. Identifying these exceptionally noisy ships, and repairing any associated damage, may result in substantial noise reduction (McKenna et al. 2013). One team suggests propeller and hull inspection every 6 months, with appropriate maintenance every time the ship is in dry dock for any reason (Renilson 2009). The only estimate we can find of the potential effect size of regular ship maintenance is a 1-2 dB reduction (Baudin \& Mumm 2015; Baudin et al. 2015a).

\section{Conclusions}

\section{$\underline{\text { Short-term }}$}

We see real-time monitoring systems as a useful part of a coordinated approach, but not as the primary or only management tool. We do not see much promise of a system expecting commanders of very large ships to make fine-scale movements on the temporal scale of minutes or the spatial scale of a few miles in the navigationally challenging waters of the Salish Sea. Unless ships can take evasive maneuvers to avoid whales at ranges $>3 \mathrm{~nm}$, we see little scope for meaningful noise reductions with minor route changes. It is more precautionary to reduce source level as part of routine operations than to presume mariners to be able to respond to real-time detections on short notice. We suspect that notices to mariners may be useful on the scale of a day (e.g., whales have or have not been seen on that day), but they are unlikely to be useful on the temporal scale of an individual ship transit through Haro Strait. By the time a ship enters Haro Strait en route to port, it may be too late or too hazardous to alter planned course or speed.

Discussions with a wider group of stakeholders, including Coast Guard and industry experts, could identify a safe way to alert mariners hours before they enter the confined waterways of Haro Strait. We see most value in adding listening stations for times of year and parts of the SRKW range that are poorly monitored by the research and whale-watching communities in Haro Strait in summer.

\section{$\underline{\text { Seasonal }}$}


Intuitively, it seems reasonable that shipping regulations should be more precautionary in summer months than in winter months, as SRKW, as well as migratory baleen whales, make use of this habitat more in the summer. In practice, identifying a date when regulations could be relaxed (a) requires input from policy makers about risk-tolerance, and (b) requires spatially and temporally explicit data on SRKW habitat use. It is our professional opinion that any effort to mitigate ship traffic is sufficiently burdensome that it should aim for year-round restrictions, to be relaxed only after new field data become available to justify relaxing those restrictions. Although SRKW use of the Salish Sea declines in winter, the whales may be more vulnerable (e.g., nutritionally stressed) in winter months than summer months.

\section{Long-term}

Long-term management measures vary in their effectiveness for a habitat like Haro Strait. It would be relatively straightforward to reach a $3 \mathrm{~dB}$ reduction in noise inputs in Haro Strait by asking all ships to slow down by $3 \mathrm{kt}$ (i.e., 100\% of the fleet affected), or imposing an $11.8 \mathrm{kt}$ speed limit for all ships (i.e., $\sim 43 \%$ of the fleet affected). A convoy approach, alone or in combination with other mitigation measures, holds strong potential to reduce median noise levels in Haro Strait and increase quiet times. With additional resources, it would be possible to reparameterize the model to estimate two biologically relevant metrics for changes in noise level. In addition to estimating the increased proportion of quieter times as a result of a convoy, it would be possible to estimate: (a) effects on echolocation (e.g., the maximum range at which an echolocating killer whale can detect the echo from a salmon, as well as the associated active volume); and (b) effects on communication calls (e.g., the maximum range at which killer whales can hear one another emitting a call, along with the associated active space).

We see limited value in fine-scale shifts in shipping lanes (e.g., on the order of $1 \mathrm{~km}$ or so). We do see value in larger-scale changes in shipping lanes (e.g., re-routing through Rosario Strait versus Haro Strait). If shifts $(<1-4 \mathrm{~km})$ in shipping lanes are pursued as a management option, we recommend they be considered in combination with other, more tractable or effective mitigation measures (e.g., speed restrictions). Rerouting ships away from Haro Strait is mathematically equivalent to removing an equal number of noisy ships from Haro Strait (described in section 1b), but the biological consequences of shifting noise sources requires additional information (beyond the scope of this review) on killer whale density, distribution, and habitat use. We see value in pursuing quieter MPAs. Given the volume of ship traffic in the region, it will be important to manage expectations, such that any decrease in noise levels inside the boundaries is considered a management and conservation success. The mechanism for generating a quieter MPA will involve the mitigation measures, singly or in combination, described throughout this review. In practice, implementation of a quieter MPA would have to include management 
of small-boat traffic as well as large ships, in light of the number of small boats watching killer whales in this region.

\section{Ship-based}

Altering ship design, both in new and existing ships, as well as adjusting shipping operations and maintenance, hold potential to reduce underwater radiated noise by $3 \mathrm{~dB}$. The simplest way to reduce the source level of a new ship is through the use of large, slow-turning propellers (Spence et al. 2007; Southall \& Scholik-Schlomer 2008; Spence \& Fischer 2016), but this topic is extremely complex (reviewed in Appendix 1). On some ships in which machinery noise dominates propeller noise, it may be possible to achieve very large $(\sim 10 \mathrm{~dB})$ noise reductions by mounting a diesel engine on a resilient foundation (Wright 2008). In most cases, the design of a quieter ship requires careful consideration of both hull and propeller design, including modelling studies at the early design stage. Modest gains can be made by choosing quieter/low-vibration machinery, or use of ducted propellers (Southall 2005).

Some technologies exist that may result in major reductions in ship noise. Ultimately, we view the difference between retrofitting and new builds as a choice driven by economic considerations.

Maintenance can also reduce noise, and is likely to improve fuel efficiency. However, the only estimate in the literature suggests that routine maintenance, in contrast to repairing major damage, is likely to lead to only modest noise reductions. Although there may be specific instances in which shipping practices are important (e.g., the choice of propeller pitch or dynamic positioning near a pilot station), adjusting most ship operating practices will generally provide less noise reduction than modest reductions in ship speed.

Recommendations:

\begin{tabular}{|l|l|l|l|l|}
\hline Option & $\begin{array}{l}\text { Management } \\
\text { option }\end{array}$ & $\begin{array}{l}\text { Achievable } \\
\text { noise } \\
\text { reduction } \\
\mathbf{( d B})\end{array}$ & Logistics & Uncertainties \& limits \\
\hline 1 & $\begin{array}{l}\text { Long-term only: } \\
\text { Convoy with 11.8 } \\
\text { knot speed limit }\end{array}$ & $\begin{array}{l}3 \mathrm{~dB} \text { for } \\
50 \% \text { of time } \\
\text { at Lime Kiln }\end{array}$ & $\begin{array}{l}\text { Pilots Association, VTSS, } \\
\text { Coast Guard }\end{array}$ & $\begin{array}{l}\text { Compliance, safety, } \\
\text { and enforcement }\end{array}$ \\
\hline 2 & Ship-based only: & $6 \mathrm{~dB}$ & Remove noisiest ships to & Logistical constraints \\
\hline
\end{tabular}




\begin{tabular}{|l|l|l|l|l|}
\hline & $\begin{array}{l}\text { Removal of noisiest } \\
\text { ships + retrofit for } \\
\text { remaining }\end{array}$ & $\begin{array}{l}\text { reduce source level by }>3 \\
\mathrm{~dB} \text { and retrofit rest of fleet } \\
\text { to reduce source level by } 3 \\
\text { dB for each ship }\end{array}$ & $\begin{array}{l}\text { with respect to time, } \\
\text { resources, and industry } \\
\text { responsiveness }\end{array}$ \\
\hline 3 & $\begin{array}{l}\text { Ship-based and } \\
\text { long-term: } \\
\text { Removal+retrofit+ } \\
\text { slow all by } 3 \text { knots }\end{array}$ & $9 \mathrm{~dB}$ & $\begin{array}{l}\text { Logistics from \#2 plus } \\
\text { VTSS \& Coast Guards } \\
\text { monitor all; Citizen } \\
\text { scientists could monitor } \\
\text { AIS; Pilots Association }\end{array}$ & $\begin{array}{l}\text { Compliance and } \\
\text { enforcement with } \\
\text { respect to the speed } \\
\text { reduction }\end{array}$ \\
\hline 4 & $\begin{array}{l}\text { Ship-based and } \\
\text { long-term: } \\
\text { Removal+retrofit+ } \\
\text { convoy at a speed to } \\
\text { get }>4 \mathrm{~dB}\end{array}$ & $>10 \mathrm{~dB}$ & $\begin{array}{l}\text { Logistics from \#3 plus } \\
\text { convoy approach could } \\
\text { impact only fast ships, or } \\
\text { certain classes }\end{array}$ & Convoy coordination \\
\hline
\end{tabular}

Table 2: the effect of combinations of strategies on the overall underwater radiated noise of vessels transiting through an area, as well as the logistics and the uncertainties and limits involved in each strategy.

A pragmatic, multi-pronged approach will (a) allow for aspirational reductions $>3 \mathrm{~dB}$ in magnitude (i.e., thereby acknowledging that biologically relevant targets are not yet known and may require mitigation $>3$ $\mathrm{dB}$ ); and (b) buffer against imperfect compliance rates, while still achieving a $3 \mathrm{~dB}$ reduction. For example, an $11.8 \mathrm{kt}$ speed limit ( $3 \mathrm{~dB}$ reduction), removal of noisiest ships ( $3 \mathrm{~dB})$, retrofitting noisy ships $(3 \mathrm{~dB})$, and managing large ship traffic in a convoy approach could collectively result in a reduction $>10$ dB. This summary table (Table 2) would lend itself to input in future models to predict population consequences of increased noise levels, or various mitigation scenarios, to SRKW.

Although our review considered only sound inputs and ignored receivers, incorporating noise mitigation efforts in recovery plans for endangered marine mammals may involve tradeoffs between amplitude and duration of noise exposure. Our convoy model suggests that a speed limit of $11.8 \mathrm{kt}$ reduces the time SRKWs receive peak levels of ship noise $(>110 \mathrm{~dB})$ by $\sim 70 \mathrm{~min} /$ day, but also decreases their "quiet time" $(<103 \mathrm{~dB}$ ) by $\sim 15-30 \mathrm{~min} /$ day. Population modelling tools are available to explore the likely consequences to SRKWs of predicted effects of noise on foraging (Lacy et al. 2017). Before evaluating this tradeoff, an explicit policy statement is needed on both the desired noise reduction target and its 
intended benefit to whales.

In 2008, the Okeanos pledge to reduce ship noise by $3 \mathrm{~dB}$ struck many of us as audacious, and seemingly unattainable. The overarching conclusion of our review and exploratory analyses is that a $3 \mathrm{~dB}$ reduction in source levels is entirely achievable among the fleet of ships operating in the Salish Sea habitat of SRKW. A modest speed reduction alone could accomplish that target, while impacting less than half of the fleet. In fact, during the time it took to compile this literature review and populate it with empirical data to gauge plausible reductions, the Port of Vancouver actually launched an ambitious trial to implement ship speed restrictions to reduce noise levels in killer whale habitat ${ }^{5}$. All commercial ships transiting Haro Strait were asked to slow to 11 knots (speed through water) from 7 August to 6 October 2017. While analyses are underway, the compliance rate appears impressive. Our analyses suggested that a speed limit of 11.8 knots should result in a $3 \mathrm{~dB}$ reduction in the contribution of shipping to noise levels in Haro Strait, which is consistent with the "Okeanos Pledge." If compliance were perfect, the Port of Vancouver's implementation of an 11 knot speed limit would exceed the targets of the "Okeanos Pledge" within the intended 10-year time frame. The issue of chronic ocean noise from shipping started to receive attention in the primary literature in the 1990s (Williams et al. 2015b), and has therefore gone from problem identification to real-world implementation of solutions in only 20 years. Here we show that combinations of mitigation measures could result in even more ambitious targets than the "Okeanos Pledge." Our analyses show that 6-10 dB reductions in ship noise are feasible in our study area using combinations of mitigation measures. Real-world implementation of various methods carry different economic costs and logistical constraints for industry, so stakeholder consultation will be needed to strike a balance among navigational safety, ecological impacts, and policy objectives. The transferability of the quantitative conclusions we draw hinge on the representativeness of the Salish Sea fleet to global shipping fleet.

In our view, our understanding of the effects of noise on killer whale foraging success remains a far greater knowledge gap than any of the knowledge gaps we outline above pertaining to physical acoustics (i.e., source level estimation and propagation modelling). This has two important implications for implementation. First, there needs to be a major investment in biological research on SRKWs to better understand the population consequences of noise and benefits of mitigation, in order to leverage fully the large investments made recently in cabled ocean observatories and physical acoustics studies to measure and predict ocean noise levels in the region (Dakin et al. 2016). Secondly, management approaches to

\footnotetext{
${ }^{5}$ https://www.portvancouver.com/environment/water-land-wildlife/marine-mammals/echo-program/vesselslowdown-trial-in-haro-strait/
} 
mitigate ocean noise in important whale habitats will have to be articulated explicitly in adaptive terms (Walters 1986), so that different tools can be used as our understanding of the issue is refined and updated with new information. Canada has made major investments on the physical acoustics side of the issue in recent years, but the uncertainty creeps in where the noise affects the whales. It is essential to couple mitigation measures with sophisticated monitoring programs of SRKW behaviour, energetics, and foraging success to ensure that the management action is achieving the desired effect. Ocean noise is a relatively tractable environmental problem to solve. Unlike issues like climate change, ocean acidification, and overfishing, ocean noise responds almost immediately to management intervention. Our review and analyses suggest that relatively modest management interventions can result in major reductions in chronic ocean noise in important whale habitats. We are encouraged by the rapid pace of research and management uptake on this important threat to the recovery of killer whales (Lacy et al. 2017).

Acknowledgements

This manuscript has benefitted from anonymous and non-anonymous comments made during the National Peer Review Meeting on the "Evaluation of the Scientific Evidence to Inform the Probability of Effectiveness of Mitigation Measures in Reducing Shipping-Related Noise Levels Received by Southern Resident Killer Whales," administered by the Canadian Science Advisory Secretariat (May 30 to June 1, 2017). In addition to the constructive verbal feedback provided to S. Veirs by the meeting participants, we are grateful for the formal reviews provided by Drs. Chris Clark and Jason Wood. Early drafts were improved through written comments provided by DFO/CSAS steering committee members and meeting participants, with particularly helpful guidance provided by Brianna Wright, Christine Erbe, Andrew Wright, Veronique Lesage, Dom Tollit, and Jack Lawson. We thank two anonymous reviewers and the $\mathrm{AE}$ at Marine Pollution Bulletin for additional feedback, which improved the clarity of the manuscript. This work was supported by a grant from Fisheries and Oceans Canada, but the views expressed here do not necessarily reflect those of DFO or Government of Canada policy. RW is supported by a Pew Fellowship in Marine Conservation. RW and EA thank Sitka Foundation for support for Oceans Initiative's Acoustic Ecology program.

\section{References}

Agardy, T. et al., 2003. Dangerous targets? Unresolved issues and ideological clashes around marine protected areas. Aquatic conservation: marine and freshwater ecosystems, 13(4), pp.353-367.

Agardy, T. et al., 2007. “A Global Scientific Workshop on Spatio-Temporal Management of Noise.” In Report of the Scientific Workshop, Vol. 51. Available at: http://www.cetaceanhabitat.org/pdf_bin/dokumentedesmeeres_report eng final_amended_v2.pdf

André, M. et al., 2011. Listening to the Deep: live monitoring of ocean noise and cetacean acoustic 
signals. Marine pollution bulletin, 63(1-4), pp.18-26.

Ashe, E., Noren, D.P. \& Williams, R., 2010. Animal behaviour and marine protected areas: incorporating behavioural data into the selection of marine protected areas for an endangered killer whale population. Animal conservation, 13(2), pp.196-203.

Audoly, C. et al., 2016. AQUO Project-Research on Solutions for the Mitigation of Shipping Noise and Its Impact on Marine fauna-Synthesis of Guidelines. In Proceedings of the 23rd International Congress on Sound and Vibration, 2016. Available at: http://www.iiav.org/archives_icsv_last/2016_icsv23/content/papers/papers/full_paper_454_20160 425171827256.pdf.

Baudin, E.B., Rousset, C. \& Audoly, C., 2015a. Underwater Noise Footprint of Shipping: The Practical Guide, AQUO: Achieving QUieter Oceans. Available at: http://www.aquo.eu/downloads/AQUO_D5.8_rev1.0_final.pdf [Accessed May 8, 2017].

Baudin, E. \& Mumm, H., 2015. Guidelines for Regulation on Underwater Noise from Commercial Shipping, AQUO/SONIC. Available at: http://www.sonicproject.eu/media/download_gallery/f68bebf80e2828939ee36d434948b88b-D5.4\%20AQUOSONIC\%20Guidelines_v4.3.pdf.

Berkowitz, H. \& Dumez, H., 2017. Racket in the oceans. Why underwater noise matters, how to measure it, and how to manage it, Paris:Observatory for Responsible Innovation / Palaiseau (France):i3-CRG (CNRS -École polytechnique). Available at: https://www.researchgate.net/publication/314442869_Racket_in_the_oceans_Why_underwater_n oise_matters_how_to_measure_it_and_how_to_manage_it [Accessed May 8, 2017].

Best, B.D., 2016. Data to Decision in a Dynamic Ocean: Robust Species Distribution Models and Spatial Decision Frameworks. Duke University. Available at: http://gradworks.umi.com/10/10/10107781.html.

Clark, C.W. et al., 2009. Acoustic masking in marine ecosystems: intuitions, analysis, and implication. Mar Ecol Prog Ser, 395: 201-222. doi: 10.3354/meps08402.

Dakin, T., Dorocicz, J., Biffard, B., Merchant, N.D., Hannay, D., Mihaly, S., Jeffries, M. and Bedard, J., 2016. Acoustic data quality assessment tools and findings for ocean observing systems. The Journal of the Acoustical Society of America, 140(4), pp.3410-3410.

DFO Canada, 2011. Recovery Strategy for the Northern and Southern Resident Killer Whales (Orcinus orca) in Canada, Fisheries and Oceans Canada. Available at: http://www.registrelepsararegistry.gc.ca/virtual_sara/files/plans/rs_epaulard_killer_whale_1011_eng.pdf.

Dolman, S.J. and Jasny, M., 2015. Evolution of marine noise pollution management. Aquatic Mammals, 41(4), p.357.

Erbe, C. et al., 2014. Identifying Modeled Ship Noise Hotspots for Marine Mammals of Canada's Pacific Region. PloS one, 9(3), p.e89820.

Ford, J.K.B., Wright B.M., Ellis, G.M., \& Candy, J.R., 2010. Chinook salmon predation by resident killer whales: seasonal and regional selectivity, stock identity of prey, and consumption rates, DFO Canada. 
Gaydos, J.K., Thixton, S. \& Donatuto, J., 2015. Evaluating Threats in Multinational Marine Ecosystems: A Coast Salish First Nations and Tribal Perspective. PloS one, 10(12), p.e0144861.

Gervaise, C. et al., 2012. Shipping noise in whale habitat: Characteristics, sources, budget, and impact on belugas in Saguenay-St. Lawrence Marine Park hub. The Journal of the Acoustical Society of America, 132(1), pp.76-89.

Hauser, Donna D.W., Logsdon, M. G., Holmes, E. E., VanBlaricom, G. R., and Osborne, R. W. 2007. Summer distribution patterns of southern resident killer whales Orcinus orca: core areas and spatial segregation of social groups." Marine Ecology Progress Series 351: 301-310.

Hall, J.D. \& Johnson, C.S., 1972. Auditory thresholds of a killer whale Orcinus orca Linnaeus. The Journal of the Acoustical Society of America, 51(2B), pp.515-517.

Hildebrand, J.A., 2009. Anthropogenic and natural sources of ambient noise in the ocean. Marine ecology progress series, 395, pp.5-20.

Holt, M.M., 2008. Sound Exposure and Southern Resident Killer Whales: A review of current knowledge and data gaps, NMFS-NWFSC.

Houghton, J. et al., 2015. The Relationship between Vessel Traffic and Noise Levels Received by Killer Whales (Orcinus orca). PloS one, 10(12), p.e0140119.

IMO-MEPC, 2009. Noise for commercial shipping and it's adverse impacts on marine life: reducing underwater noise pollution from large commercial vessels, Available at: https://www.nrdc.org/sites/default/files/wat_14050501a.pdf.

IWC Scientific Committee, 2016. Report of the Workshop on Acoustic Masking and Whale Population Dynamics, Bled, Slovenia: International Whaling Commission.

Jasny, M., 2005. Sounding the depths II: The rising toll of sonar, shipping and industrial ocean noise on marine life. Natural Resources Defense Council.

Lacy, Robert C., et al., 2017. Evaluating anthropogenic threats to endangered killer whales to inform effective recovery plans. Scientific reports 7.1: 14119.

Leaper, R., Calderan, S. \& Cooke, J., 2015. A Simulation Framework to Evaluate the Efficiency of Using Visual Observers to Reduce the Risk of Injury from Loud Sound Sources. Aquatic Mammals, 41(4), pp.375-387.

Leaper, R., Renilson, M., \& Ryan, C. 2014. Reducing Underwater Noise from Large Commercial Ships: Current Status and Future Directions. Journal of Ocean Technology (9):1. Available at: http://search.ebscohost.com/login.aspx?direct=true\&profile=ehost\&scope=site\&authtype=crawler \&jrnl=17183200\&AN=95846538\&h=HnGgvltyT4fzxuRUwoAFioh3Q8aX141 naC8CF7n6px\%2 BSTWTrT9CpM2Tv6UJlU393O3pCtkmBJVmdLpkHgB0NsQ\%3D\%3D\&crl=c.

Lusseau, D. et al., 2009. Vessel traffic disrupts foraging behaviour of southern resident killer whales. Endangered species research, 6, pp.211-221.

Margules, C.R. \& Pressey, R.L., 2000. Systematic conservation planning. Nature, 405(6783), pp.243253. 
Marine Mammal Commission, 2007, March. Marine mammals and noise: a sound approach to research and management. In Report to Congress from the Marine Mammal Commission, March.

McKenna, M.F., Wiggins, S.M. \& Hildebrand, J.A., 2013. Relationship between container ship underwater noise levels and ship design, operational and oceanographic conditions. Scientific reports, 3. Available at: http://www.ncbi.nlm.nih.gov/pmc/articles/PMC3641522/ [Accessed August 23, 2013].

Miller, D.L. et al., 2013. Spatial models for distance sampling data: recent developments and future directions. Methods in ecology and evolution / British Ecological Society, 4(11), pp.1001-1010.

Radford, A.N., Kerridge, E. and Simpson, S.D., 2014. Acoustic communication in a noisy world: can fish compete with anthropogenic noise?. Behavioral Ecology, 25(5), pp.1022-1030.

Redfern, J.V. et al., 2013. Assessing the risk of ships striking large whales in marine spatial planning. Conservation biology: the journal of the Society for Conservation Biology, 27(2), pp.292-302.

Renilson, M.R., 2009. Reducing underwater noise pollutions for large commercial vessels, International Fund for Animal Welfare. Available at: http://www.ifaw.org/unitedstates/node/1129.

Rolland, R.M. et al., 2012. Evidence that ship noise increases stress in right whales. Proceedings of the Royal Society B: Biological Sciences, (February). Available at:

http://rspb.royalsocietypublishing.org/cgi/doi/10.1098/rspb.2011.2429.

Ross, D. 1976. Cavitation. Mechanics of underwater noise: 202-242.

Silber, G.K. et al., 2012. The role of the International Maritime Organization in reducing vessel threat to whales: Process, options, action and effectiveness. Marine Policy, 36(6), pp.1221-1233.

Simmonds, M.P., Dolman, S.J., Jasny, M., Parsons, E.C.M., Weilgart, L., Wright, A.J. and Leaper, R., 2014. Marine noise pollution-increasing recognition but need for more practical action.

Southall, B.L., 2005. Shipping noise and marine mammals: A forum for science, management, and technology, US Department of Commerce, National Oceanic and Atmospheric Administration, National Marine Fisheries, Service, Office of Protected Resources. Available at: http://www.beamreach.org/wiki/images/4/47/2004NoiseReport.pdf [Accessed October 30, 2013].

Southall, B.L. \& Scholik-Schlomer, A., 2008. Potential application of vessel-quieting technology on large commercial vessels. In Final Report of the National Oceanic and Atmospheric Administration (NOAA) International Conference. 1-2 May, 2007, NOAA Fisheries, Silver Spring, MD.

Spence, J. et al., 2007. Review of existing and future potential treatments for reducing underwater sound from oil and gas industry activities. NCE Report, pp.07-001.

Spence, J.H. \& Fischer, R.W., 2016. Requirements for Reducing Underwater Noise From Ships. IEEE Journal of Oceanic Engineering, PP(99), pp.1-11.

Szymanski, M.D. et al., 1999. Killer whale (Orcinus orca) hearing: auditory brainstem response and behavioral audiograms. The Journal of the Acoustical Society of America, 106(2), pp.1134-1141.

Vanderlaan, A. et al., 2008. Reducing the risk of lethal encounters: vessels and right whales in the Bay 
of Fundy and on the Scotian Shelf. Endangered species research, 4, pp.283-297.

Veirs, V., 2017. A QT program to model underwater sounds from commercial shipping. https://github.com/veirs/convoy_0

Veirs, S. et al., 2017. A key to quieter seas: half of ship noise comes from $15 \%$ of the fleet. Available at: 10.22541/au.149039726.69540798 [Accessed March 28, 2017].

Veirs, S., Veirs, V. \& Wood, J.D., 2016. Ship noise extends to frequencies used for echolocation by endangered killer whales. PeerJ, 4, p.e1657.

Veirs, V. \& Veirs, S., 2006. Average levels and power spectra of ambient sound in the habitat of Southern Resident orcas. NOAA/NMFS/NWFSC. Available at:

http://www.nwfsc.noaa.gov/research/divisions/cb/ecosystem/marinemammal/documents/veirs_no aa_haro_noise_final.pdf [Accessed May 1, 2014].

Vélez-Espino, L.A. et al., 2014. Relative importance of chinook salmon abundance on resident killer whale population growth and viability. Aquatic conservation: marine and freshwater ecosystems. Available at: http://onlinelibrary.wiley.com/doi/10.1002/aqc.2494/abstract [Accessed August 26, 2014].

Walters, C.J., 1986. Adaptive management of renewable resources. Macmillan Publishers Ltd.

Ward, E.J., Holmes, E.E. \& Balcomb, K.C., 2009. Quantifying the effects of prey abundance on killer whale reproduction. The Journal of applied ecology, 46(3), pp.632-640.

Weilgart, L.S., 2007. The impacts of anthropogenic ocean noise on cetaceans and implications for management. Canadian journal of zoology, 85(11), pp.1091-1116.

Williams, R. et al., 2013. Acoustic quality of critical habitats for three threatened whale populations. Animal conservation.

Williams, R. et al., 2009. Effects of vessels on behaviour patterns of individual southern resident killer whales Orcinus orca. Endangered species research, 6(March), pp.199-209.

Williams, R. et al., 2015. Quiet(er) marine protected areas. Marine pollution bulletin. Available at: http://www.sciencedirect.com/science/article/pii/S0025326X1530028X [Accessed September 23, 2015].

Williams, R., Wright, A.J., Ashe, E., Blight, L.K., Bruintjes, R., Canessa, R., Clark, C.W., CullisSuzuki, S., Dakin, D.T., Erbe, C. and Hammond, P.S., 2015. Impacts of anthropogenic noise on marine life: publication patterns, new discoveries, and future directions in research and management. Ocean \& Coastal Management, 115, pp.17-24.

Williams, R. et al., 2014a. Severity of killer whale behavioral responses to ship noise: A doseresponse study. Marine pollution bulletin, 79(1-2), pp.254-260.

Williams, R. et al., 2014b. Marine mammals and ocean noise: future directions and information needs with respect to science, policy and law in Canada. Marine pollution bulletin, 86(1-2), pp.29-38.

Williams, R., Lusseau, D. \& Hammond, P., 2006. Estimating relative energetic costs of human disturbance to killer whales (Orcinus orca). Biological conservation, 133(3), pp.301-311. 
Wright, A.J., 2008. International Workshop on Shipping Noise and Marine Mammals, Hamburg, Germany: Okeanos - Foundation for the Sea. Available at: http://www.sound-in-thesea.org/download/ship2008_en.pdf. 